Arq. Bras. Med. Vet. Zootec., v.56, n.1, p.32-35, 2004

\title{
Doença periapical em eqüinos: estudo de quatro casos
}

\author{
[Periapical disease in equine: study of four cases] \\ G.M. Pagliosa ${ }^{1}$, G.E.S. Alves $^{2}$, H.P. Oliveira ${ }^{2}$, V.A Gheller ${ }^{2}$, C.E. Braga ${ }^{2}$ \\ ${ }^{1}$ Mestranda em Cirurgia Veterinária na EV/UFMG \\ ${ }^{2}$ Escola de Veterinária da UFMG \\ Caixa Postal 567 \\ 30123-970 - Belo Horizonte, MG
}

\begin{abstract}
RESUMO
Estudaram-se quatro casos de doença periapical (DP) em eqüinos submetidos à apicectomia e extração dentária. O diagnóstico baseou-se na anamnese, nos exames físico geral e oral e na radiologia. A apicectomia foi ineficaz devido à falta de tratamento endodôntico e a extração dentária mostrou-se a melhor conduta de tratamento, apesar da dificuldade de cura completa da infecção. A DP pode ter causas adicionais a serem definidas, além das classificadas como primária e secundária pela literatura.
\end{abstract}

Palavras-chave: eqüino, doença periapical, extração dentária, apicectomia

\begin{abstract}
Four cases of periapical disease (PC) in equines submitted to apicoectomy and dental extraction were studied. The diagnosis was based on anamnesis, physical and oral examination and radiology. The apicoectomy was not effective due of the lack of endodontic treatment. The dental extraction was the better treatment, despite of the difficulty of complete cure of the infection. The PC can have other causes, beyond of those classified as primary and secondary by the literature.
\end{abstract}

Keywords: horse, periapical disease, dental extraction, apicoectomy

\section{INTRODUÇÃO}

A doença periapical (DP) é uma das afecções dentárias mais graves em eqüinos. Pode ser de origem primária em eqüinos de até sete anos de idade (Schumacher, Honnas, 1993) ou secundária a afecções das estruturas relacionadas ao ápice dentário (Dixon, 1997).

Os sintomas clínicos variam de acordo com a idade e o dente afetado, sendo freqüente o emagrecimento, cólicas por impactação, queda de alimento durante a mastigação, halitose, epífora e problemas de adaptação à embocadura (Mueller, 1991; Lane, 1994). O sinal clínico mais evidente é o aumento de volume facial ou mandibular assimétrico, com ou sem corrimento nasal ou fístula (Schumacher, Honnas, 1993).

O diagnóstico deve basear-se na anamnese, no exame clínico e na avaliação radiológica para descartar outras causas de aumento de volume facial ou mandibular (Dixon, 1997).

Recebido para publicação em 18 de março de 2003

Recebido para publicação, após modificações, em 25 de outubro de 2003

*Autor para correspondência

Av. Novara, $n^{\circ}$ 61, Bloco 06, Apto. 301, B. Bandeirantes

31340-460 - Belo Horizonte, MG

E-mail: geanepagliosa@bol.com.br 
O tratamento depende do grau de comprometimento do ápice e do dente, podendo ser conservativo ou cirúrgico, mediante apicectomia ou extração, que é a mais praticada.

O objetivo deste trabalho foi relatar e discutir quatro casos de DP em eqüinos.

\section{CASUÍSTICA}

\section{Eqüino 1}

Garanhão da raça Mangalarga Marchador de sete anos de idade com aumento de volume facial esquerdo (Fig. 1), de quatro meses de evolução, período em que foi feito tratamento tópico com vários produtos. Ao exame físico, o eqüino apresentou as características clínicas nos limites fisiológicos e aumento de volume facial semiesférico de aproximadamente $10 \mathrm{~cm}$ e consistência dura. Ao exame radiológico verificou-se área de radioluscência em torno do ápice do dente M1, compatível com doença periapical.

$\mathrm{Na}$ cirurgia realizou-se aspiração de líquidos seroso e hemorrágico, provenientes do volume facial. Pela abordagem cirúrgica do volume, foi aberto o seio maxilar, constatando-se a presença de abscesso em continuidade com os ápices dos dentes M1 e PM4, além de osteólise parcial maxilar. A apicectomia foi realizada devido à ausência de alterações visíveis em estruturas orais ou periodonto e pela presença do abscesso. Após debridamento de tecidos necrosados e lavagem do seio, a ferida cirúrgica foi suturada, mantendo-se um dreno capilar.

O pós-operatório constituiu de limpeza do dreno e terapia à base de antibiótico e antiinflamatório. Houve cicatrização adequada e recomposição óssea maxilar, porém com evolução de fístula.

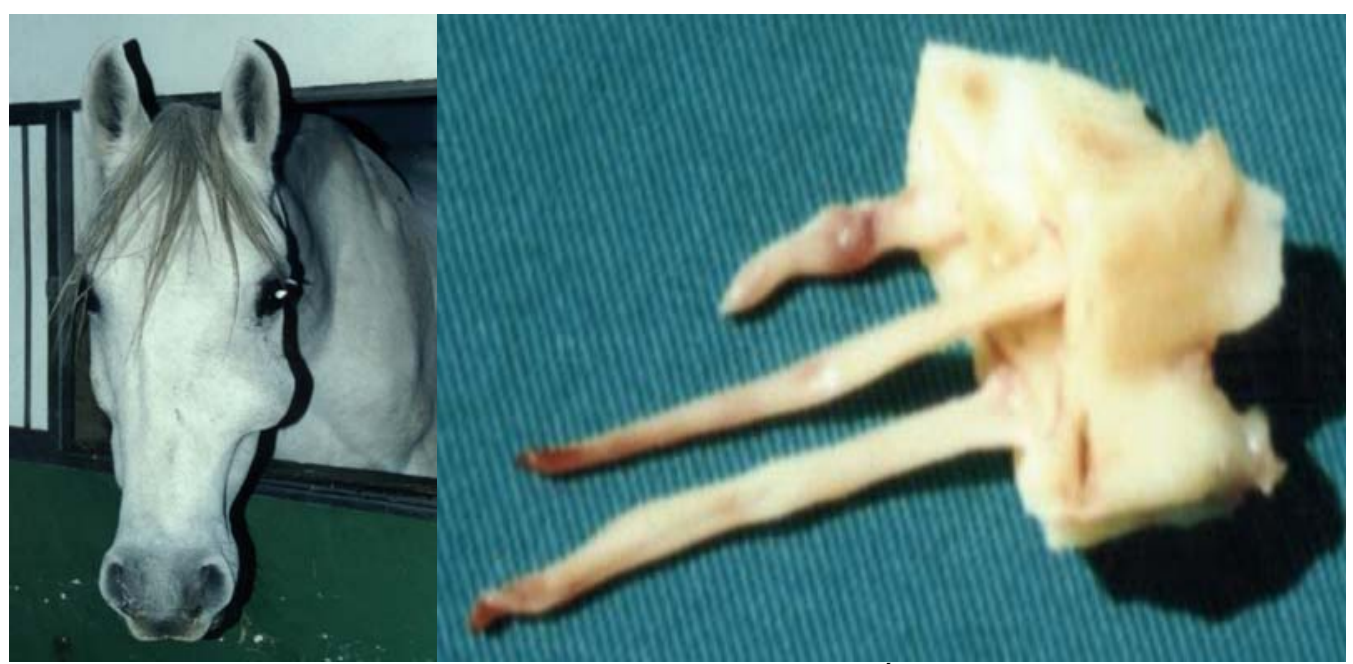

Figura 1. Aumento de volume facial devido à doença periapical. Ápice dentário removido, evidenciando os cornos pulpares (direita).

\section{Eqüino 2}

Égua da raça Brasileiro de Hipismo de quatro anos de idade, portadora de fístula purulenta na borda ventral da mandíbula esquerda, de cinco meses de evolução, período em que se fez tratamento conservativo local com iodopovidona ${ }^{1}$ e solução fisiológica ${ }^{2}$, e parenteral

\footnotetext{
${ }^{1}$ Asterine: Áster Produtos Médicos Ltda. Sorocaba, SP
}

com antibioticoterapia. $\mathrm{O}$ exame radiológico confirmou a presença de doença periapical no dente PM3. Realizou-se apicectomia devido à ausência de alterações em estruturas orais e no periodonto.

\footnotetext{
${ }^{2}$ Cloreto de sódio 0,9\%: Fresenius Kabi Brasil Ltda. Campinas, SP.
} 
No pós-operatório foram administrados enrofloxacina $^{3}$ durante 10 dias e flunixin meglumine ${ }^{4}$ por cinco dias. O dreno foi mantido por 72 horas e a ferida cirúrgica foi tratada com solução de permanganato de potássio ${ }^{5}$ e rifocina ${ }^{6}$.

Após sete meses, devido à permanência da fístula, foram realizadas extrações dos dentes PM3 e PM4 devido ao comprometimento avançado. $\mathrm{O}$ pós-operatório foi conduzido conforme o primeiro caso, acrescido de metronidazol $^{7}$ por via oral do $10^{\circ}$ ao $20^{\circ}$ dia de pós-operatório e lavagem oral diária. A ferida cirúrgica foi mantida com um dreno capilar, trocado a cada 24 horas. Aos 21 dias de pósoperatório verificou-se granulação na ferida e aos 53 dias houve cicatrização completa.

\section{Eqüino 3}

Égua da raça Brasileiro de Hipismo de três anos e meio de idade, portadora de fístula relacionada ao dente PM3 mandibular esquerdo, mantida sob tratamento conservador até a regressão com formação de crosta ocorrida depois de dois meses. Um ano e meio após, houve recidiva da fístula com secreção purulenta, sendo então extraído o dente PM3.

O pós-operatório seguiu-se com antibioticoterapia à base de penicilina $^{8} \mathrm{e}$ gentamicina $^{9}$ e tratamento local com permanganato de potássio e solução fisiológica. Aos 43 dias de pós-operatório, após desenvolver granulação com secreção discreta durante três semanas, a fístula passou a drenar exsudato em maior quantidade e o eqüino apresentou halitose. A ferida passou a ser tratada com ácido metacresolsulfônico gel ${ }^{10}$. Dois meses e meio após a cirurgia, ainda havia uma pequena fístula que drenava menos exsudato.

\footnotetext{
${ }^{3}$ Duotril 10\%: Duprat. Rio de Janeiro, RJ.

${ }^{4}$ Banamine: Ind. Quím. e Farm. Shering-Plough S/A. Rio de Janeiro, RJ.

5 Permanganato de K: Farmax Produtos Farmacêuticos. Divinópolis, MG.

${ }^{6}$ Rifocina $500 \mathrm{mg}$ : Hoescht Marion Roussel S/A. Suzano, SP.

${ }^{7}$ Canfiden: Green Pharma Quím. e Farm. Ltda. Anápolis, GO.

8 Agrovet 5.000.000: Novartis Saúde Animal Ltda. São Paulo, SP.

${ }^{9}$ Gentocin: Ind. Quím. e Farm. Shering-Plough S/A. Rio de Janeiro, RJ.

${ }^{10}$ Albocresil: Byk Química e Farmacêutica Ltda. Diadema, SP.
}

\section{Eqüino 4}

Égua da raça Quarto de Milha de três anos de idade, portadora de fístula mandibular relativa à DP do M1 direito, submetida a cirurgia de extração dentária. Após quatro meses, retornou com sintomas de dificuldade de mastigação associada à queda na alimentação, sialorréia intensa e halitose. Pelo exame físico evidenciouse aumento de volume no ramo mandibular esquerdo relativo ao cisto de erupção do PM4, confirmado pelo exame radiológico. Observouse, ainda, presença de capas dos dentes PM3 e PM4 maxilares esquerdos e uma esquírola óssea na ferida cirúrgica alveolar. Procedeu-se à retirada das capas e da esquírola óssea seguida de lavagem oral com iodopovidona diluída e aplicação de iodo a 5\% na ferida alveolar.

O pós-operatório seguiu-se com metroniadazol oral. Houve melhora progressiva dos sintomas clínicos.

\section{DISCUSSÃO}

A ausência de cistos de erupção e alterações orais no eqüino 1 descarta a possibilidade de doença periapical primária e secundária, sugerindo outras possibilidades etiológicas, como traumatismo, sinusite e hiperparatireoidismo secundário nutricional, não relacionadas na literatura consultada. A sinusite maxilar presente constitui complicação adicional, freqüente em casos de doença periapical crônica nos dentes com raízes alojadas no seio maxilar (Dixon, 2000).

O tratamento conservador mostrou-se ineficaz nos eqüinos 2 e 3 , fato já salientado por Dixon (2000) que o considerou eficaz só nos casos de doença periapical em dentes mandibulares, na ausência de fístulas. A doença periapical nos dentes pré-molares e molares mandibulares geralmente ocorre em eqüinos jovens, restringindo-se ao ápice dentário, sendo raro o envolvimento de estruturas orais (Dixon, 2000), o que coincide com os casos dos eqüinos 2 e 4 . No entanto, a demora para o tratamento cirúrgico deve ter sido a razão para o comprometimento dentário, conforme ocorreu no eqüino 3.

A apicectomia é uma técnica indicada em casos de doença periapical sem envolvimento de 
estruturas orais, como nos eqüinos 1 e 2 . No entanto, deve ser seguida de tratamento endodôntico (Dixon, 1997), o que explica a falta de êxito ocorrida nos dois casos.

A cicatrização por segunda intenção após extrações dentárias é um processo demorado devido à contaminação e cruência cirúrgica. Por isso, antibióticos de amplo espectro e antiinflamatórios estão indicados, além de curativo diário na ferida alveolar com soluções antissépticas e quimioterápicos seguido de impactação com bucha de gaze (Lowder, 1999). Durante o pós-operatório, o eqüino pode desenvolver complicações como diminuição do apetite, halitose, fístulas, osteomielite e até carcinoma odontogênico (Lilich, 1998). A halitose foi observada no eqüino 3 , concomitante com o aumento de secreção na ferida cirúrgica, e no eqüino 4 devido ao acúmulo de alimento pela dificuldade de mastigação. A presença da esquírola óssea no eqüino 4 deveu-se à cruência cirúrgica conseqüente da extração dentária por repulsão que pode ocasionar pequenas fraturas no osso alveolar (Prichard et al., 1992).

\section{CONCLUSÕES}

A DP tem causas adicionais a serem definidas, além das classificadas e descritas como primária e secundária. Em eqüinos acometidos de DP, a dificuldade de cura completa da infecção pode permanecer após a extração dentária. A apicectomia sem tratamento endodôntico não deve ser realizada, mesmo nos casos de doença periapical sem alterações de estruturas orais. A extração dentária permanece como melhor conduta para tratar a doença periapical secundária, devendo também ser feita quando não for possível a apicectomia associada ao tratamento endodôntico, em eqüinos com doença periapical primária.

\section{REFERÊNCIAS BIBLIOGRÁFICAS}

DIXON, P.M. Dental extraction in horses: indications and preoperative evaluation. Equine Vet. Educ., v.19, p.366-375, 1997.

DIXON, P.M.; TREMAINE, W.H.; PICKLES, K. et al. Equine dental disease part 4: a long-term study of 400 cases: apical infections of cheek teeth. Equine Vet. J., v.32, p.182-194, 2000.

LANE, J.G. A review of dental disorders of the horse, their treatment and possible fresh approaches to management. Equine Vet. Educ., v.6, p.13-21,1994.

LILICH, J.D. Complications of dental surgery. Vet. Clin. North Am., v.14, p.399-410, 1988.

LOWDER, M.Q. Oral extraction of equine teeth. Comp. Cont. Educ. Prac. Vet., v.21, p.11501157, 1999.

MUELLER, P.O. E. Equine dental disorders: cause, diagnosis, and treatment. Comp. Cont. Educ. Prac. Vet, v.13, p.1451-1460, 1991.

PRICHARD, M.A.; RICHARD, P.H.; ERB, H.N. Long-term outcome of tooth repulsion in horses: a retrospective study of 61 cases. Vet. Surg., v.21, p.145-149, 1992.

SHUMACHER, J.; HONNAS, C.M. Dental surgery. Vet. Clin. North Am., v.9, p.133-152, 1993. 